Some of the infectious diseases that were the prime concern of the W.H.O. in its early days after the second world war have yielded to the attack made on them, but smallpox stands out as capable of springing some nasty surprises, as we have seen in Britain from time to time. Earlier this year, as the latest annual report from the Regional Office recalls, ${ }^{1}$ it struck in Yugoslavia, causing no fewer than 175 cases and 33 deaths in the first outbreak that country had experienced for 42 years. The infection was brought in by a pilgrim returning from Iraq, where he had visited a number of holy places. $^{2}$ Only one case outside the country followed from this outbreak-namely, in West Germany.

A more insidious threat comes from cholera. After 50 years of freedom from the disease it has again, in the words of the report, "implanted itself" in Europe. Three cases were recorded in Britain in 1971 as a result of infection in Spain, and the El Tor biotype has gained such a firm even though small hold on Europe that further cases can only be expected. Certainly it is a disease to be taken seriously, ${ }^{3}$ for symptomless excreters can spread it as they can typhoid fever, and early diagnosis and treatment are all-important for cure. The other fast-increasing infectious disease, gonorrhoea, is also of concern to the W.H.O., and representatives from European countries have met to exchange information on control measures.

The W.H.O. now also sponsors or co-ordinates research into many non-communicable diseases which at the same time can be aptly described as epidemic, and most prominent among these is coronary artery disease. About a million people are estimated to have died of it in the year covered by the report. Individual countries, including Great Britain, are financing research into this disease and its companion disorders. The role of the W.H.O. is to help the national centres plan their research programmes without duplication of work and with some conjunction of aim. 1971 was the first year of full-scale study, and by the end of it information on more than 9,000 cases of myocardial infarction had been collected. This study is continuing. Complementary to it is W.H.O.'s work on the care of patients before, during, and after ischaemic heart attacks. As well as advising on research projects it has sent experts to a number of countries to help in the establishment of coronary care units.

Among W.H.O.'s many other projects it has held meetings on water pollution, air pollution, the work of laboratory services, and the disposal of waste. It sees its role increasingly as helping the co-ordination of health policies at national level, and it is evident from the support it continues to receive that its work is invaluable to many individual institutions as well as more broadly to the public health of the countries themselves.

\footnotetext{
1 World Health Organization, Regional Office for Europe, Report of the Regional Director Fuly 1971 to Fune 1972. Copenhagan, W.H.O., 1972.

2 Dorolle, P, Lancet, 1972, 2, 525

3 British Medical fournal, 1972, 2, 62.
}

\section{New Thoughts on Nursing}

It is just over 50 years since nurses obtained professional recognition through State registration, and during this half century of vast social change, world war, and technical advance in medicine an increasingly complex suprastructure has been erected on this qualification. Many circumstances now combine to make a radical revision of the nursing situation acceptable. Problems of recruitment, wastage, education, and staffing are widespread. Application of the Salmon Report has not always been painless. Morale is low in some sectors. The Seebohm Report has had its side effects for the community nurses, and the projected reorganization of the Health Service in 1974 will be an instrument of change. Now that the Briggs Report ${ }^{1}$ is at last available, nurses can consider their problems as a whole and begin to work and plan for the future.

The Committee on Nursing, whose appointment was announced by the Secretary of State for Social Services (then Mr. R. Crossman) on 2 March 1970, recommends that the functions of the General Nursing Council and the Central Midwives Board should be merged in a new Central Nursing and Midwifery Council, with the midwives' interests specially represented by a standing committee of the new council. There would be three nursing and midwifery education boards for England, Wales, and Scotland, and area committees for nursing and midwifery education would be formed under each board. Nurse-midwife education would remain under the aegis of the Department of Health and Social Services, despite some pressure to have them transferred to the education departments. It was felt that students would be better off financially if they were not in receipt of grants, that the manpower studies necessary to control student intake would have to be done by the Health Departments, and that there is a need to co-ordinate health and social policy.

The age of entry to training, it is thought, should be reduced to $17 \frac{1}{2}$ in 1973, and to 17 in 1975. Students will enrol in colleges of nursing and midwifery. The Report envisages 200-300 such colleges, which would mean the eventual disappearance or amalgamation of many nursetraining schools. Each college would have a principal, with a staff of senior lecturers, lecturers, and clinical tutors, and the principle would be free to employ non-nurses as teachers. Tutors in the colleges would be independent of the service structure of hospitals, and the principal would be responsible through a governing body to the area education committee.

Students should no longer be considered as part of the labour force of the hospitals in which they obtain clinical experiences. There would be for all entrants one basic course of 18 months, leading to the certificate of nursing practice. This course would consist of "modules" of combined clinical and theoretical experience in general and psychiatric nursing of all age groups in hospital and in the community. The certificate would be taken by prospective midwives as well as nursing students. Suitability is not to be determined only by possession of O-level passes, and students will possess a wide range of intelligence, "from average to the highest." No uncertificated student will be left in charge of a ward at night.

Those who wish to go on may take a second 18-months course, leading to State registration. This can be followed by higher certificates in various nursing specialties. Able students may include study for a higher certificate in their registration course. The roll of nurses will disappear, and the register will include all trained nurses, so that the present separate registers for general, paediatric, psychiatric, and mental handicap specialists will be abolished.

All midwives will be nurses. Those on the register may take a 12-months course leading to registration as a midwife and the award of a higher certificate, while those with only the certificate of nursing practice will take an 18-months 
course. A nationally agreed syllabus and planned in-service training is advocated for nursing aides, who will, it is envisaged, form one-third of the labour force in nonpsychiatric hospitals in 10 years time, when students no longer rank as pairs of hands.

An increase in the number of qualified nurse-teachers is essential to the fulfilment of such a schems, and their numbers have been growing only slowly. It it proposed that the new qualification will be the diploma in nursing and midwifery education, the course for which will last one year. It is felt that during the transition period formal entrance requirements will have to be waived. This will cause misgiving among nurse-teachers, since it must mean that a generation of tutors will become registered who will be less well educated than many of their students.

Questions will inevitably arise about the position of special hospitals, and whether the clinical skill of (for instance) paediatric and psychiatric nurses can be maintained. It is expected that most students will work in paediatric wards, some spending a substantial part of their time there, and that there will be opportunities by way of the higher certificate for those wishing to work with children either in hospital or in the community. Difficulties already exist in the midwifery situation but it is not believed that these are insuperable. The role of the mature entrant, whom it is hoped to attract in larger numbers, is stressed. Lowering the age of entry will affect the orthopaedic, ophthalmic, and thoracic nursing intakes, but it is believed that a higher certificate in such fields will attract trained staff. Psychiatric hospitals will benefit from an influx of students taking their basic courses and through the provision of higher certificates. Hope for the evolution of a social type of care for the mentally handicapped is expressed in rather reserved terms.

The field of community nursing care rightly receives much attention, and the diversity of opinions is recognized. The committee believes that the related but distinct skills of the home nurse and the health visitor are both necessary, and foresees their continuance. The family clinical sister will be a registered nurse with a higher certificate in community clinical nursing, and the family health sister will have a higher certificate in community preventive nursing. One of the great problems of the community health field will be the provision and supervision of clinical experience for all students who need it.

This survey can do no more than draw attention to some of the outstanding recommendations. The committee has considered also in a realistic way manpower, recruitment, working conditions, the position of male nurses, immigrants, and assimilation problems. It conducted some research and its report is a mine of information on many related topics. Chapters 2 and 3 give the views of nurses and students on aspects of their work, including medical attitudes and practices that affect it adversely. Stress is laid throughout on the quality of care, and the importance of forward planning to prevent management staggering from one crisis to another. The commonly held view that the problems of the nursing profession would disappear if there were more nurses and midwives is challenged. The full impact of this dense, interesting, and constructive report on those concerned cannot be assessed immediately. The first reaction of nurses seems to be cautious friendliness, and now different groups will have to consider their own positions in the suggested new structure. In this context the following words from the report are apt: "Nursing and midwifery is more than a work force. It is a profession, and creative concern for developing professional standards in a changing society can itself be a powerful lever for change."

1 Committee on Nursing (chairman, Professor Asa Briggs), Report, Cmnd. 5115. London, H.M.S.O., 1972

\section{Safety of Medicines}

The number of adverse reactions to drugs reported to the Committee on Safety of Drugs and to its successor, the Committee on Safety of Medicines, continues to decrease, according to the latest report from the latter body. ${ }^{1}$ The committee expresses concern over this, though it considers that part of the decline in 1971 from 1970 may be attributed to the postal strike. The number reported in 1971 was 2,837, which were 764 fewer than the previous year. Since the reporting of adverse reactions cannot be anything like complete, the interpretation to be put on the numi $\rightarrow r s$ of reports and their trends up or down must be guarded. But oddly enough the committee does not mention one possible explanation for the decrease, and that is that adverse reactions are actually becoming fewer. In so far as they are due to faulty or too general prescribing of potentially toxic remedies they may have diminished in frequency as the undoubted growth of postgraduate and continuing education has made doctors more aware of the hazards. But doctors in turn certainly have an obligation to report adverse reactions to the committee, for unless they do so the committee cannot keep them informed of the ill effects from this or that drug that their colleagues are observing.

During the year evidence came to the committee that the topical administration of corticosteroids to pregnant animals could cause fetal abnormalities. The relevance of this finding to human beings has not been established, but manufacturers of preparations for human use agreed, after discussions with the committee, to include the advice in their leaflets that topical steroids should not be prescribed in large amounts or for long periods for pregnant women.

This first report of the Committee on Safety of Medicines continues the series that came from its predecessor on Safety of Drugs. The composition of the two committees is the same but the second replaced the first on 1 September 1971 in its capacity as a statutory committee under the Medicines Act, 1968. Its job is to advise on the "safety, quality and efficacy" of medicines for human use and to promote "the collection and investigation of information relating to adverse reactions."

\footnotetext{
1 Committee on Safety of Medicines, Report for the Year Ended 31 December 1971. London, H.M.S.O., 1972. Members of the Committee: Professor E. F. Scowen (chairman), Professor W. I. Cranston, Professor T. Crawford, Professor C. T. Dollery, Dr. D. C. Garratt, Sir Austin Bradford Hill, Professor D. R. Laurence, Dr. M. J. Linnett, Professor P. N. Magee, Professor W. W. Mushin, Professor D. V. W. Parke, Professor W. Linford Rees Wilson.
} 